\title{
Laboreal
}

Volume 15 N$^{\circ} 2$ | 2019

Varia

\section{A Psicologia do trabalho e as Clínicas do trabalho no Brasil}

La Psicología del trabajo y las Clínicas del trabajo en Brasil

La Psychologie du travail et les Cliniques du travail au Brésil

Work psychology and the work clinics in Brazil

José Newton Garcia de Araújo e Vanessa Andrade de Barros

\section{(2) OpenEdition}

Journals

Edição electrónica

URL: http://journals.openedition.org/laboreal/15515

DOI: $10.4000 /$ laboreal.15515

ISSN: 1646-5237

\section{Editora}

Universidade do Porto

Refêrencia eletrónica

José Newton Garcia de Araújo e Vanessa Andrade de Barros, «A Psicologia do trabalho e as Clínicas do trabalho no Brasil », Laboreal [Online], Volume $15 \mathrm{~N}^{0} 2$ | 2019, posto online no dia 01 dezembro 2019, consultado o 10 abril 2020. URL : http://journals.openedition.org/laboreal/15515; DOI : https:// doi.org/10.4000/laboreal.15515

Este documento foi criado de forma automática no dia 10 abril 2020.

Laboreal está licenciado com uma Licença Creative Commons - Atribuição-NãoComercial 4.0 Internacional. 


\title{
A Psicologia do trabalho e as Clínicas do trabalho no Brasil
}

\author{
La Psicología del trabajo y las Clínicas del trabajo en Brasil \\ La Psychologie du travail et les Cliniques du travail au Brésil \\ Work psychology and the work clinics in Brazil
}

José Newton Garcia de Araújo e Vanessa Andrade de Barros

\section{NOTA DO EDITOR}

Manuscrito recebido em julho/2019

Aceite após peritagem novembro/2019

\section{Introdução}

1 Este texto tem como horizonte os trabalhos inscritos por pesquisadores brasileiros no "Simpósio França-América Latina", em 2018, em Havana. Em torno de 50 propostas, nem todas apresentadas no evento, seus títulos e resumos versavam sobre conceções, campos e conteúdos diversos, o que exigiu a escolha metodológica de elegermos um campo disciplinar e procedermos a um recorte por temas e perspetivas que mais sobressaíram, tanto pela qualidade da abordagem quanto pela quantidade de trabalhos. Destacamos o campo da Psicologia do trabalho, em suas interfaces com a saúde do trabalhador e com as perspetivas das Clínicas do trabalho, a partir de um recorte orientado pela leitura de títulos, resumos e referências dos estudos submetidos. Daí buscamos breves referências históricas dessas disciplinas, no Brasil, e retomamos os eixos temáticos do simpósio, elencando algumas contribuições das pesquisas apresentadas, sem, no entanto, nos determos na análise de suas temáticas. 


\section{Breves notas sobre os antecedentes da Psicologia do trabalho no Brasil}

2 É difícil traçar um panorama completo da psicologia do trabalho, no Brasil, dada a extensa produção advinda de diferentes correntes teóricas, metodológicas e deontológicas, nos últimos cinquenta anos, bem como de suas conexões com outras disciplinas no campo das ciências humanas e sociais, assim como no campo das ciências da saúde. Certamente, ao tentar alinhavar um histórico dessas produções, estaremos deixando de contemplar algumas delas.

Uma observação inicial a se fazer diz respeito a uma divisão teórico-metodológica, no terreno das psicologias que se ocupam do trabalho. De um lado, está a tradição das psicologias cognitiva e experimental que, fundadas nas premissas do neopositivismo e que visam à previsão e controle do desempenho do trabalhador (Bendassolli \& Soboll, 2011); de outro lado, situaríamos as demais correntes filiadas grosso modo a uma perspetiva social, política e clínica, identificadas a uma psicologia social crítica do trabalho. Dentre essas últimas, destacamos produções inspiradas na psicossociologia francesa (Barus-Michel, Enriquez, \& Lévy, 2002), as correntes institucionalistas (Lourau, 1970 ; 1975 ; Lapassade, 1967 ; 1977 ; Deleuze \& Guattari, 1972 ; 2010), Mendel (1998), entre outras abordagens críticas que se apoiam nas heranças marxista, freudiana, freudomarxista e mesmo foucaultiana, que seguem orientando grande parte dos estudos atuais no campo da psicologia crítica. No campo institucional, lembremos ainda as influências do pensamento engajado dos italianos Berlinguer (1976), Basaglia (1985) e Jervis (2019).

4 Sobre a Psicossociologia, tomada aqui como uma das orientações basilares da Psicologia do trabalho, é oportuno lembrar que ela foi introduzida no Brasil a partir dos contatos com pesquisadores franceses trazidos por Célio Garcia, professor de psicologia social do Departamento de Psicologia da Universidade Federal de Minas Gerais (UFMG), desde o final dos anos de1960. Citemos, a exemplo, as visitas de Max Pagès, em 1979 e André Levy, em 1997. Nesse período, a Psicossociologia também se fazia conhecer, entre nós, por intermédio da A.R.I.P. (Association pour la Recherche et l'Intervention Psychosociologique) e de suas publicações na revista Connexions. Através dessa corrente teórica e metodológica, que tinha em Kurt Lewin um de seus inspiradores, uma nova perspetiva de análise foi introduzida nos estudos e nas intervenções junto às organizações, nas quais os problemas ligados direta ou indiretamente ao trabalho sempre ocuparam um lugar de destaque. No início dos anos de 1970, tivemos a presença de George Lapassade, que introduziu entre nós a análise institucional, desenvolvida com René Lourau. Mais ou menos à mesma época, sempre por intermédio de Célio Garcia, estiveram entre nós Michel Foucault e Cornelius Castoriadis. Dentre as produções brasileiras, Peter Spink (1997) já na década de 1970 apontava os aspetos psicossociais do trabalho. Uma divulgação básica da Psicossociologia, no Brasil, se deu através da publicação do livro Psicossociologia: Análise Social e intervenção (Machado, Moura Castro, Araújo, \& Roedel, 1994, 2001), com textos de André Lévy, André Nicolaï, Eugène Enriquez e Jean Dubost.

5 A ênfase que damos a esses pensadores no escopo deste artigo deve-se ao fato de que se constituem nas bases orientadoras que construíram o pensamento psicossociológico sobre o trabalho na atualidade. 
6 No início da década de 1990, os contatos de pesquisadores brasileiros com a Psicossociologia tiveram continuidade por meio do CIRFIP (Centre International de Recherche, de Formation et d'Intervention Psychosociologiques). Vale lembrar que diversos pesquisadores-docentes, alocados em universidades brasileiras de norte a sul do país, fizeram sua formação doutoral em instituições universitárias francesas, sendo posteriores os contatos dos doutorandos e pós doutorandos psicólogos com o Conservatoire National des Arts et Métiers (CNAM). Tais influências foram marcantes nos trabalhos submetidos ao simpósio.

7 A partir de 2001 até 2011, realizaram-se, na UFMG, em Belo Horizonte, Minas Gerais, diversos colóquios internacionais de psicossociologia e a sociologia clínica. Esses eventos também ocorreram, anos depois, em outras universidades brasileiras, como a Universidade Federal de Santa Catarina (UFSC) e a Universidade de Brasília (UnB). Nesses eventos, além dos já citados André Lévy e Eugène Enriquez, figuram também os nomes de Jacqueline Barus-Michel, Gilles Amado, Dominique Lhuilier, Vincent de Gaulejac, Robert Castel, Robert Sévigni, Jacques Réhaume, Pierre Roche, para citar apenas alguns. Mesmo que esses colóquios não visassem discutir as questões ligadas diretamente ao trabalho, estas eram fartamente contempladas, em meio a outras temáticas, envolvendo grupos, organizações, instituições e comunidades, com incursões específicas em questões da atualidade, como minorias, gênero, feminismo, vulnerabilidade social, educação, infância, trabalho rural, políticas públicas, sustentabilidade, imigração, configurando os cenários sociopolíticos, em cujo interior o trabalho, direta ou indiretamente, ocupa um lugar privilegiado.

8 Tais temáticas se desdobraram, ao longo dos anos, constituindo-se atualmente em atividades de pesquisas relacionadas diretamente ao trabalho, acompanhando problematizações de movimentos e grupos que interrogam o mundo laboral, a partir de focalizações específicas, como por exemplo : raça, gênero e trabalho ; sustentabilidade e trabalho; juventude e trabalho; migrações e trabalho, trabalho em contextos de grandes riscos e exposições a produtos tóxicos, trabalhos em locais e situações marginalizados, home office, trabalho no setor de serviços, em bancos, em aplicativos, tudo isso transversalmente inserido em âmbitos mais amplos, como direitos humanos, políticas publicas, saúde, educação, violência, exclusão, corpo, desenvolvimento tecnológico, precarização e fragilização da vida, criatividade, formação e transmissão.

\section{O campo da Saúde do trabalhador e sua interface com a Psicologia do trabalho}

9 Um dos temas que mais se destacaram no simpósio foi a interação entre esses campos Saúde do Trabalhador e Psicologia do trabalho - considerando momentos políticos distintos da historia brasileira.

10 O campo da saúde do trabalhador surgiu, no Brasil, na década de 1980, à época da chamada abertura política, com a presença de sindicatos e do movimento sanitário, do qual participavam profissionais da saúde, inclusive psicólogos, levando a Constituição Federal a incorporar políticas públicas voltadas à saúde do trabalhador (Esteves, Bernardo, \& Sato, 2017, p. 55). Esse campo de saberes e práticas, continuam os autores, se inspirou nos princípios da Saúde Coletiva e, em especial, na Medicina Social latinoamericana (Laurell \& Noriega, 1989 ; Matrajt, 2013), que tomavam a saúde como parte 
do processo histórico e social, tendo o trabalho como categoria explicativa central. Neste contexto, também foram realizados no Brasil desenvolvimentos da teoria do desgaste, de Laurell, de modo a ser consubstanciada a perspetiva teórica do desgaste mental relacionado ao trabalho (Seligmann-Silva, 1994 e 2011).

De fato, foi no bojo da retomada da luta dos movimentos sindicais chamados autênticos, base do novo sindicalismo brasileiro, que o campo da saúde do trabalhador ganha relevo, especialmente com a criação, em São Paulo, do Departamento Intersindical de Estudos e Pesquisas de Saúde e dos Ambientes de Trabalho (Diesat) no qual, como aponta Sato (2010) engenheiros, advogados, ergonomistas, sociólogos, psiquiatras, sanitaristas, médicos do trabalho e psicólogos, passam a olhar para o mundo do trabalho através dos problemas de saúde. A atuação profissional de psicólogos em órgãos sindicais e em órgãos de saúde pública fortaleceu essa nova forma de olhar os problemas e demandas dos trabalhadores e seus órgãos de representação, que se constituem como protagonistas da luta pela saúde do trabalhador.

Importante ressaltar que essa inserção inicial de psicólogos na saúde publica e em órgãos de defesa dos trabalhadores representa sólida base de atuação da psicologia do trabalho, no campo de políticas publicas que, atualmente, são referência de práticas psicológicas de saúde e atenção, nas redes SUS (Sistema Único de Saúde), SUAS (Sistema Único de Assistência Social), RENAST (Rede Nacional de Atenção Integral à Saúde do Trabalhador), CEREST's (Centros Estaduais e Regionais de Referência em Saúde do Trabalhador), CAPS (Centro de Atenção Psicossocial), CERSAM's (Centro de Referência em Saúde Mental), CRAS (Centro de Referência de Assistência Social), CREAS (Centro de Referência Especializado de Assistência Social) e NASF's (Núcleos de Apoio à Saúde da Família). Nesse sentido, a Portaria oㅜ 1.823, de 23 de agosto de 2012, do Ministério da Saúde, que "institui a Política Nacional de Saúde do Trabalhador e da Trabalhadora " abre frentes importantes de atuação da psicologia do trabalho, sobretudo na esfera da saúde mental.

13 Sato (2010) também comenta que a abordagem crítica de Laurell e Noriega traz os elementos orientadores no campo da Saúde do Trabalhador, analisando a categoria trabalho, através do conceito de processo de trabalho, central para a compreensão da dinâmica saúde-doença, além de compreendê-lo como uma atividade que se desenvolve num processo histórico. Tal posição serviu de suporte teórico para um diálogo interdisciplinar, além de sustentar "práticas profissionais em diálogo com trabalhadores e trabalhadoras e seus órgãos de representação política" (Sato, 2010, p. 45). Essa perspetiva, norteada pela Psicologia social do trabalho, situa o campo disciplinar da psicologia voltado ao trabalhador, em sua dimensão histórico-política, distinguindo-o das abordagens positivistas, individualizantes e a serviço dos modelos gerencialistas de intervenção. É de se destacar igualmente que as práticas de pesquisa e intervenção em Saúde do Trabalhador, no Brasil, também tiveram como fonte o chamado Modelo Operário Italiano, apresentado nos anos 70 por Ivar Oddone e sua equipe (Oddone, Re, \& Briante, 1981); tal abordagem recoloca o trabalhador como protagonista da análise do trabalho, através de sua participação efetiva, naquela invenção metodológica que Oddone et al. (1981) denominaram "comunidade científica ampliada".

14 Assim é que podemos situar a formação de um novo campo de saberes e práticas voltadas, no Brasil, para a saúde do trabalhador, tendo como base as relações da psicologia social com o campo do trabalho. Demarcando-se da psicologia clínica e da 
psicologia da saúde, esse campo toma a saúde do trabalhador como importante terreno de pesquisa de uma psicologia social "que buscava tanto compreender quais aspetos dos processos de trabalho levavam a adoecimento dos trabalhadores quanto identificar formas de enfrentá-los" (Esteves, Bernard, \& Sato, 2017, p. 57).

Aqui situamos um grupo de docentes e pesquisadores, cuja identificação teórica e metodológica ficou conhecida como Psicologia social do trabalho. Este grupo, em 1998, criou a revista Cadernos de Psicologia Social do Trabalho, vinculada ao Departamento de Psicologia social e do trabalho, do Instituto de Psicologia da Universidade de São Paulo (USP). As publicações desta revista se tornaram uma referência para estudantes, docentes e pesquisadores da área do trabalho. Além dessa revista, mencionemos a obra "Psicologia social do trabalho", organizada por Maria Chalfin Coutinho, Márcia Hespanhol Bernardo e Leny Sato, lançada em 2017 e que sintetiza o pensamento crítico, as pesquisas e as ações deste mesmo grupo.

Outras interfaces significativas da Psicologia do trabalho dizem respeito ao campo da medicina do trabalho, e suas conexões internas com a medicina social, preventiva e da saúde coletiva, no Brasil (Seligmann-Silva, 2011 ; Lacaz, 2016), e seus intercâmbios com as pesquisas, intervenções, assessorias e formações desenvolvidas pela FUNDACENTRO (Fundação Jorge Duprat Figueiredo de Segurança e Medicina do Trabalho), voltadas à prevenção em ambientes de trabalho e à saúde do trabalhador. A Revista Brasileira de Saúde Ocupacional - RBSO, publicada por esta fundação é uma referencia na área. Importante mencionar também os trabalhos de Selma Lancman e de Teresa Mitsunaga, esta ultima precursora dos estudos em saúde do trabalhador na região nordeste brasileira.

\section{Psicologia do trabalho, intercâmbios com as Clínicas do trabalho e outros saberes}

As chamadas Clinicas do trabalho, a saber : a Psicodinâmica do trabalho, a Clínica da atividade, a Ergologia e a Psicossociologia do trabalho, tiveram significativo destaque, em termos de perspetivas teórico-metodológicas dos trabalhos aprovados no "Simpósio França-América Latina, em especial aqueles relativos a estudos sobre agravos à saúde do trabalhador e ao campo da saúde mental e trabalho.

Destas abordagens clínicas, a Psicodinâmica do trabalho (Dejours, 1996) foi a precursora no Brasil. Posteriormente, passamos a conhecer a Clínica do trabalho (Clot, 2006) e a Ergologia (Schwartz \& Durrive, 2010 ; 2015), enquanto a Psicossociologia do trabalho (Lhuilier, 2014), apesar de sua originalidade, já tinha certa familiaridade com o público brasileiro, em função de sua precedente filiação com a psicossociologia tout court. Essas correntes tiveram especial divulgação com o livro Clinicas da Atividade (Bendassolli \& Soboll, 2011).

19 A obra A Loucura no trabalho (Dejours, 1987) marcou uma inflexão nos estudos sobre o trabalho, no Brasil, na medida em que introduziu na chamada 'Psicologia organizacional' análises sobre a relação saúde e trabalho e os impactos da organização do trabalho no psiquismo. Essa obra foi de grande utilidade, posto que inspirou a criação de novos modelos de intervenção e reflexões do campo da saúde mental e trabalho - e aqui não podemos deixar de mencionar a influência dos precursores 
franceses Paul Sivadon (1957), Claude Veil (2012) e, principalmente, Louis Le Guillant (2006).

20 Suas críticas ao taylorismo igualmente levaram à construção de novos modos de pensar o trabalho nas organizações, chegando no Brasil em um momento já impactado pelo avanço das novas tecnologias computadorizadas, nos processos produtivos, com efeitos na saúde e na organização dos trabalhadores. Havia, à época, um sentimento de perda real do conteúdo do trabalho, fonte de grande preocupação do movimento sindical que ressurgia no fim da ditadura militar no Brasil.

Outra disciplina desse campo das clínicas é a Clínica da atividade, desenvolvida a partir de 1990, na França, por Yves Clot e Daniel Faïta gozando de enorme recetividade nos meios acadêmicos brasileiros. Desde 2007, Yves Clot participa frequentemente de eventos no Brasil, tendo sido sua obra divulgada, além de numerosos artigos e capítulos de livros, com a publicação de A função psicológica do trabalho (2006) e Trabalho e poder de agir (2010). Segundo Silva, Barros de Barros e Louzada (2011), os conceitos e metodologias da Clínica da atividade têm sido utilizados, no Brasil, "em múltiplas composições... e outros modos de produzir interferências/conhecimentos que já estavam aqui mais ou menos sedimentados" (p. 200). Diversos eventos científicos sobre a Clínica da atividade têm sido realizados no Brasil, dentre os quais três edições do Colóquio Internacional da Clínica da atividade- CICA, nas cidades de São João del Rei (2010), Natal (2013) e São Paulo (2016).

22 Além da Clínica da atividade, observa-se, no Brasil, grande influência da Ergologia, que se iniciou, conforme afirmam Athayde e Brito (2011) por meio de contatos de pesquisadores brasileiros com a Université de Provence, onde trabalhava Yves Schwartz. A relação com este autor se intensificou, a partir de sua primeira vinda ao Brasil, em 1997, aí se incluindo missões científicas junto a organismos dedicados à questão do trabalho, onde se destaca um acordo Capes / Cofecub, em 1997, que possibilitou a realização de doutorados de pesquisadores brasileiros na Université AixMarseille. A partir daí foram realizados intercâmbios pontuais (cursos, participação em pesquisas conjuntas, organização de eventos, etc., principalmente no Rio de Janeiro, São Paulo e Minas Gerais), com profissionais brasileiros de diferentes formações acadêmicas, em diversas regiões do Brasil, além de cooperação com organismos intersindicais, como o Dieese/SP, a Escola Sindical Sete de Outubro/MG e o Cesat/BA. Assim, houve um aumento de pesquisas e publicações inspirados na Ergologia, nos cursos de graduação e pós-graduação brasileiros, com predominância de "investigações vinculando o trabalho à Linguística, Psicologia social, Ergonomia, Engenharia de produção, Educação, Saúde pública, Comunicação, Administração" (Athayde \& Brito, 2011, p. 273), o que evidencia o crescimento de pesquisas interdisciplinares, focando questões específicas do mundo do trabalho, com diversas experimentações no campo da pesquisa-intervenção. A tradução dos livros Trabalho e ergologia: conversas sobre a atividade humana (Schwartz \& Durrive, 2010) e Trabalho e Ergologia II - Diálogos sobre a atividade humana (Schwartz \& Durrive, 2015) por grupos de pesquisadores do Rio de Janeiro e de Minas Gerais trouxe enorme impacto nas pesquisas desenvolvidas no que podemos chamar de transdisciplinariedades do trabalho.

Quanto à Psicossociologia do trabalho, sua afirmação como campo disciplinar autônomo é mais recente, mesmo que ela guarde as anteriores vinculações com a clássica Psicossociologia francesa. Esse campo tem se consolidado no Brasil por meio de um intercâmbio intenso com Dominique Lhuilier, presente em inúmeros eventos 
realizados em diversas universidades brasileiras. Lhuilier tem também recebido significativo número de doutorandos e pós-doutorandos brasileiros, no Conservatoire Nacional des Arts et Métiers (CNAM), além de contar uma vasta publicação de artigos e capítulos de livros, no Brasil. Em 2012 e 2015 foram realizados, na Universidade Federal de Minas Gerais, o primeiro e segundo Colóquio internacional de Psicossociologia do trabalho. Cabe salientar a importante iniciativa de Dominique Lhuilier, juntamente com Andréa Pujol, da Universidad Nacional de Córdoba (Argentina), que foi justamente a organização deste Simpósio França-América Latina, intitulado "Subjetividade e trabalho - entre mal-estar e bem-estar : construção de um novo paradigma da saúde no trabalho". Este Simpósio teve o grande mérito de reunir, provavelmente pela primeira vez, um grande contingente de pesquisadores brasileiros com colegas de uma dezena de países latino-americanos, além de numerosos pesquisadores franceses e canadenses.

Dentre outros intercâmbios internacionais que enriqueceram as pesquisas sobre a Psicologia do trabalho, no Brasil e que possuem interfaces com as perspetivas clínicas e críticas, citemos também a presença de Marianne Lacomblez, da Universidade do Porto, que atuou, em 2014, como professora visitante da Universidade Federal Fluminense (UFF), tendo também trabalhado, antes e após esta visita, com diversos outros programas de pós-graduação, no país. Um pouco de sua sólida trajetória intelectual pode ser apreciado na entrevista que ela concedeu à revista Cadernos de Psicologia Social do Trabalho (Lacomblez, Araújo, Zambroni-de-Souza, \& Máximo, 2016). Cabe lembrar aqui que o seu nome está ligado também à revista Laboreal, que é igualmente uma referência na divulgação da psicologia crítica do trabalho e das disciplinas afins, na Europa e na América Latina, com grande penetração no Brasil.

Voltando ao contexto nacional, na impossibilidade de elencar todos os intercâmbios da Psicologia do trabalho, cabe mencionar, de passagem, as aproximações da Psicologia do trabalho com a Sociologia do trabalho, representada especialmente por Ricardo Antunes (2018), lembrando o quanto essas parcerias têm sido férteis, no campo da pesquisa e de sua consequente produção teórica. Aqui acrescentamos as colaborações com a economia (Marcio Pochmann, João Antônio de Paula) e muito especialmente com a ergonomia (Leda Leal Ferreira, Laerte Sznelwar, Seiji Uchida, Selma Lancman, Francisco Lima), cujos trabalhos possuem articulações importantes com a Psicodinâmica do trabalho, para citar apenas alguns.

\section{Pesquisas brasileiras}

Tendo em vista a enorme variedade temática dos trabalhos brasileiros submetidos ao Simpósio França-América Latina, podemos afirmar que esses trabalhos possuem forte convergência, no que se refere à orientação ético-política presente nas conceções de homem e sociedade. Conforme já indicamos, é um desafio identificar peculiaridades dos estudos brasileiros, embora elas sejam inegáveis. Limitamo-nos a observar que, em consonância com muitas pesquisas internacionais, elas focalizam, entre outros temas, o desgaste físico e psíquico dos trabalhadores, impactados pelo agravamento da precarização, intensificação e individualização do trabalho. Isso ocorre com o fortalecimento de políticas neoliberais traduzidas, grosso modo, por novas e variadas formas de contratação e de remuneração, pelo desmonte dos marcos regulatórios das relações de trabalho, pela perda do sentido do trabalho e por modelos gerenciais 
coercitivos e opressores, embutidos na ideologia da excelência e da captura de subjetividades, em tempos de produção flexível.

De fato, os avanços de políticas de ajuste económico, de desmantelamento da solidariedade e de formas de cooperação no trabalho, configuram situações de enorme violência institucional que têm como alvo os trabalhadores e suas organizações. Tudo isso incide diretamente no processo de saúde-doença do trabalhador tanto nos setores formais quanto informais da economia, como indicou um grande número dos estudos apresentados.

Outros, por sua vez, apontaram a necessidade de resistência e de protagonismo dos trabalhadores, mesmo que incipientes, visíveis na construção de novas formas de viver e trabalhar, buscando fazer frente às metamorfoses atuais do mundo laboral. Citem-se aqui trabalhos sobre a participação em organizações e ações comunitárias; novas formas de trabalho educativo; o uso do trabalho como resistência à violências de gênero, raça e classe - tanto no sentido de que o ato de trabalhar se configura como resistência em sí, empoderando o/as trabalhadores quanto como locus de organização de maneiras de resistir às diferentes formas de violência - a participação em movimentos militantes; a desconstrução de modos instituídos de trabalhar ; a criação de redes de cuidado e proteção social.

Tivemos assim um conjunto de temáticas que, embora variadas, tendem todas à mesma orientação social e crítica. No que diz respeito às perspetivas teóricas e metodológicas apresentadas, os trabalhos possuem ampla diversidade, traduzindo a polissemia que contém a noção de trabalho. A prevalência de referenciais da Psicologia do trabalho, em diálogo com Clínicas do trabalho e com outras disciplinas - Medicina, Sociologia, Economia, Teorias críticas da administração de empresas e Ergonomia da atividade configura um mosaico onde os autores recorreram a uma disciplina única ou a mais de uma, buscando um diálogo entre elas.

Elencamos, a seguir, os temas abordados nos trabalhos apresentados nos 05 eixos temáticos, observando que se trata de uma divisão meramente didática, posto que os temas são transversais e complementares. Em comum, eles trazem, de maneira mais ou menos evidenciada, as conflitualidades presentes nas finalidades do trabalho, do nivel micro da atividade ao macro das politicas e regulações, convocando diferentes disciplinas para dar conta de suas problemáticas.

1. Diretamente relacionados à saúde, temos os trabalhos que tratam prioritariamente de: problemas relativos à inserção de pessoas com deficiência no trabalho; o presenteísmo ou o escondimento do adoecimento, por medo de perder o trabalho; os problemas de saúde dos trabalhadores da saúde pública, no combate a endemias urbanas; os transtornos mentais e comportamentais do trabalhador, em tempos de reestruturação produtiva; a saúde e o adoecimento mental do trabalhador dos serviços de atenção básica, no sistema brasileiro de saúde (SUS, CERESTs, CAPS, CERSAM's) ; as relações entre trabalho e uso de drogas ; saúde e adoecimento do trabalhador do setor público; problemas que atingem os profissionais de reabilitação profissional, no serviço público brasileiro ; sofrimento e saúde de trabalhadores eletricitários ; políticas de reabilitação profissional ; a saúde do trabalhador que lida com adolescentes em conflito com a lei, o uso de substâncias psicoativas no trabalho.

2. No eixo relativo às políticas neoliberais e precarização do trabalho, temos : trabalho formal, informal e precarizado; efeitos perversos da gestão neoliberal na vida do trabalhador; a precarização do trabalho do professor universitário do setor privado ; impactos do modelo de gestão por indicadores quantitativos da produção sobre a subjetividade e a saúde do trabalhador ; a precarização do trabalho do teleatendente ; a lógica de funcionamento das 
universidades corporativas : formação ou formatação profissional (hiperespecialização) e seus efeitos sobre a subjetividade; os efeitos da reforma trabalhista brasileira na saúde do trabalhador ; a questão da terceirização ; a carreira de mulheres executivas e os problemas de sua qualidade de vida.

3. As questões contemporâneas relacionadas ao trabalho e à políticas publicas aparecem em estudos que privilegiam os temas: corpo e trabalho; o problema do assédio moral nos setores público e privado ; questões ligadas ao trabalho dos servidores do poder judiciário ; o trabalho de professores no ensino especial de jovens e adultos (EJA); a experiência e os desafios de ex-atletas na função de gestores de empresa; o trabalhador e a reprodução assistida, em situações de maternidades tardias; questões envolvendo os efeitos do racismo no mercado de trabalho : as cotas para negros na universidade, o mito da democracia racial no Brasil, diferenças salariais entre trabalhadores negros e brancos ; normativas de gênero e de trabalho; trabalho e riscos psicossociais em empresas públicas e privadas; o poder de agir e os conflitos sobre critérios relativos ao "trabalho bem feito", em agentes comunitários ; causas de sobrevivência e mortalidade das atividades produtivas informais ; construção da intersetorialidade no campo saúde e trabalho.

4. No eixo resistências, apontamos os trabalhos: as formações coletivas como agente de mudanças no trabalho, em um hospital universitário; estratégias coletivas de saúde em servidores hospitalares ; a dominação e a resistência do coletivo de trabalhadores ; a reforma agrária, cooperação e resistência dos assentados ; terceirização e formas de resistência.

5. Em trabalhos com relevância para as questões metodológicas observamos a prevalência de pesquisas orientadas por historias de vida e de trabalho e uma oficina de fotos : a trajetória de vida e o gesto profissional no campo da psiquiatria; história de vida e transição profissional; história de vida e problemas de gênero, no caso de mulheres trabalhadoras portadoras de HIV ; trabalho, violência e suicídio.

31 Entendemos que todos os eixos são perpassados pela questão central do trabalhador (aí incluído o pesquisador) que é aquela referente ao sentido e ao significado do trabalho, enquanto uma práxis e um construto teórico essencial à compreensão do mundo do trabalho e seus desdobramentos na vida psíquica e político-social.

\section{Considerações finais}

Os contatos, eventos e intercâmbios acadêmicos, acima referidos, possibilitaram uma enorme divulgação das Clínicas do trabalho no Brasil, particularmente em suas conexões com a Psicologia social do trabalho. Atualmente, há diversos grupos e laboratórios de pesquisas, em todo o país, ligados a essas disciplinas e/ou autores, sendo a sua difusão bastante ampla, não apenas nos cursos de psicologia, mas em outros programas de ensino, pesquisa e extensão, ligados à saúde do trabalhador, (medicina do trabalho, psiquiatria, enfermagem, terapia ocupacional, fisioterapia), à engenharia de produção, à ergonomia da atividade, ao direito e à administração de empresas, demonstrando a necessidade, importância e riqueza da transdisciplinaridade, nos estudos relativos ao trabalho.

Assinalamos ainda que a presença das abordagens clínicas do trabalho e da Psicologia social do trabalho têm lugar de destaque entre os pesquisadores da ANPEPP (Associação Nacional de Pesquisa em Pós-graduação em Psicologia), com diversos Grupos de Trabalho (GT's) dedicados especificamente à problemática clínica, social e política, a partir dos problemas ligados ao mundo do trabalho. Entre esses GT's, citamos os seguintes : Modos de vida e trabalho : ciência, cotidiano e democracia ; Psicodinâmica e 
Clínica do trabalho; Psicossociologia do trabalho ; Trabalho e processos organizativos na contemporaneidade; Trabalho e saúde.

Esperamos, finalmente, embora não tenhamos discutido esta questão ao longo do texto, que as diferenças teóricas e metodológicas entre as abordagens acima apresentadas, em lugar de provocar os desgastantes conflitos institucionais ou grupais, levem a debates acadêmicos aprofundados que explicitem sempre mais a riqueza de seus fundamentos epistemológicos e façam valorizar a importância da diversidade, tanto no campo científico quanto nas demais esferas do campo social.

\section{BIBLIOGRAFIA}

Athayde, M., \& Brito, J. (2011). Ergologia e clínica do trabalho. In P. F. Bendassolli \& L. A. Soboll (Orgs), Clínicas do trabalho : novas perspectivas para compreensão do trabalho na atualidade. (pp. 258-282). São Paulo :Atlas.

Antunes, R. (2018). o privilégio da servidão : o novo proletariado de serviços na era digital. São Paulo : Boitempo editorial.

Barus-Michel, J., Enriquez, E., \& Lévy, A. (2002) Vocabulaire de Psychosociologie, références et positions. Ramonville Saint-Ange : Érès Éditions. https://doi.org/10.3917/eres.barus.2002.01

Basaglia, F. (1985). A instituição negada : relato de um hospital psiquiátrico. Rio de Janeiro : Graal.

Bendassolli, P. F., \& Soboll, L. A. ( 2011). Clínicas do trabalho : novas perspectivas para compreensão do trabalho na atualidade. São Paulo: Atlas.

Berlinguer, G. (1976). Psiquiatria e poder. Belo Horizonte : Interlivros.

Clot, Y. (2006). A função psicológica do trabalho. Petrópolis : Vozes.

Clot, Y. (2010). Trabalho e poder de agir. Belo Horizonte : FabreFactum.

Dejours, C. (1987). A loucura no trabalho. São Paulo : Oboré.

Dejours, C. (1996). Introduction, psychodynamique du travail. Revue Internationale de Psychosociologie, 3(5), 5-15.

Deleuze, G., \& Guattari, F. (2010). O Anti-Édipo : capitalismo e esquizofrenia. São Paulo : Editora 34.

Esteves, E., Bernardo, M. H., \& Sato, L. (2017). Fontes do pensamento e das práticas em Psicologia social do trabalho. In : M. C. Coutinho, M. H. Bernardo \& L. Sato (Orgs). Psicologia social do trabalho (pp. 49-80). Petrópolis : Vozes.

Jervis, G. (2019). Manual crítico de psiquiatria. Barcelona : Editorial Anagrama.

Lacaz, F. A. C. (2016). Continuam a adoecer e morrer os trabalhadores : as relações, entraves e desafios para o campo Saúde do Trabalhador. Revista Brasileira de Saúde Ocupacional, 41(13), 1-11. http://dx.doi.org/10.1590/2317-6369000120415

Lacomblez, M. H., Araújo, A. J., Zambroni-de-Souza, P. C., \& Máximo, T. A. (2016). Marianne Lacomblez e a construção de uma Psicologia da Atividade de Trabalho. Cadernos De Psicologia Social Do Trabalho, 19(1), 121-133. https://doi.org/10.11606/issn.1981-0490.v19i1p121-133 
Lapassade, G. (1967). Groupes, organisations et institutions. Paris : Gauthier-Villars.

Lapassade, G. (1977). Grupos, Organizações e instituições. Rio de Janeiro : Livraria Francisco Alves.

Laurell, A. C., \& Noriega, M. (1989). Processo de produção e saúde. Trabalho e desgaste operário. São Paulo : Cebes - Hucitec.

Le Guillant, L. (2006). Escritos de Louis Le Guillant - da Erogoterapia à Psicopatologia do trabalho. Petrópolis : Vozes.

Lhuilier (2014). Introdução à psicossociologia do trabalho. Cadernos de Psicologia

Social do Trabalho, 17(1), 5-19. DOI : 10.11606/issn.1981-0490.v17ispe1p5-19

Lourau, R. (1970). L'analyse institutionnelle. Paris : Minuit.

Lourau, R. (1975). A análise institucional. Petrópolis : Vozes.

Machado, M. N. M., Moura Castro, E., Araújo, J. N. G., \& Roedel, S. (1994). Psicossociologia : análise social e intervenção. Petrópolis : Vozes.

Machado, M. N. M., Moura Castro, E., Araújo, J. N. G., \& Roedel, S. (2001). Psicossociologia : análise social e intervenção Belo Horizonte : Ed. Autêntica.

Matrajt, M. (2013). Travail, subjectivité et société. México : Subjetividad y Cultura.

Mendel, G. (1998). L'Acte est une aventure : du sujet métaphysique au sujet de l'acte pouvoir. Paris :

Éditions La Découverte.

Oddone, I., Re, A., \& Brianti, G. (1981). Redécouvrir l'expérience ouvrière : vers une autre psychologie du travail ? Paris : Messidor/Éditions Sociales.

Sato, L. (2010) Psicologia, saúde e trabalho : distintas construções dos objetos "trabalho" e “organizações”. In A. I. Leonardi, C. C. C. Netto, C. Moreira, C., D. C. Façanha, K. Eidelwein, \& R. Oliveira (Orgs). Psicologia crítica do trabalho na sociedade contemporânea (pp. 41 - 53). Brasília : Conselho Federal de Psicologia.

Schwartz, Y., \& Durrive, L. (2010). Trabalho e ergologia : conversas sobre a atividade humana. Niterói : EdUFF.

Schwartz, Y., \& Durrive, L. (2015). Trabalho e ergologia II : conversas sobre a atividade humana. Belo Horizonte : Fabrefactum.

Seligmann-Silva, E. (1994). Desgaste mental no trabalho dominado. São Paulo : Cortez editora.

Seligmann-Silva, E. (2011). Trabalho e desgaste mental : o direito de ser dono de si mesmo. São Paulo : Cortez editora.

Silva, C. O., Barros de Barros, M. E., \& Louzada, A. P. F. (2011). Clínica da atividade : dos conceitos às apropriações no Brasil. In P. F. Bendassolli \& L. A. P. Soboll, L. A. P. (Org.) Clinicas do trabalho novas perspectivas para compreensão do trabalho na atualidade (pp. 188-207). São Paulo: Atlas.

Sivadon, P. (1957). Psychiatrie du travail. In H. Desaille (Org.). Cours de médecine du travail (pp. 405-420). Paris : Le François, T. II.

Spink, P. K. (1997). Organização como fenômeno psicossocial : notas para uma redefinição da psicologia do trabalho. Psicologia \& Sociedade, 8(1), 174-192.

Veil, C. (2012). Vulnérabilités au travail - naissance et actualité de la psychopathologie du travail. Toulouse : Éditions Érès. https://doi.org/10.3917/eres.veil.2012.01 


\section{RESUMOS}

Este artigo apresenta uma breve discussão sobre a Psicologia do trabalho no Brasil e suas interfaces com as Clínicas do trabalho e com o campo da saúde do trabalhador. Nosso ponto de partida são os trabalhos inscritos por pesquisadores brasileiros no "Simpósio França-América Latina". Um recorte metodológico permitiu-nos eleger esses campos disciplinares, por meio da leitura de títulos, resumos e referências dos trabalhos apresentados. Os textos evidenciaram uma significativa convergência entre aos seguintes temas : a orientação social e crítica, no interesse pelos sujeitos trabalhadores; a complexidade e as singularidades que regem suas experiências laborais; os processos de constituição, os engajamentos psíquicos e político-sociais desses trabalhadores. Acreditamos que uma síntese das pesquisas apresentadas neste colóquio reflete o estágio atual da Psicologia do trabalho no Brasil, em suas conexões com as Clínicas do trabalho e com o campo da Saúde do trabalhador.

Este artículo presenta una breve discusión sobre la Psicología del trabajo en Brasil y sus interfaces con las Clínicas del trabajo y el campo de la salud del trabajador. Nuestro punto de partida son los trabajos registrados por investigadores brasileños en el "Simposio FranciaAmérica Latina". Un recorte metodológico nos permitió elegir estos campos disciplinarios mediante la lectura de títulos, resúmenes y referencias de los trabajos presentados. Los textos evidencian una convergencia significativa entre los siguientes temas : la orientación social y crítica en el interés de los sujetos trabajadores; la complejidad y singularidades que rigen sus experiencias laborales; los procesos de constitución, los compromisos psíquicos y políticosociales de estos trabajadores. Creemos que una síntesis de las investigaciones presentadas en este coloquio refleja el momento actual de la Psicología del trabajo en Brasil, en sus conexiones con las Clínicas del trabajo y con el campo de la Salud del trabajador.

Cet article présente une brève discussion sur la Psychologie du travail au Brésil et ses interfaces avec les Cliniques du travail et le champ de la Santé du Travailleur. Les travaux présentés par les chercheurs brésiliens au "Symposium France-Amérique Latine" constituent notre point de départ. Ces champs disciplinaires ont été définis à partir d'une analyse des titres, des résumés et des références des communications présentées. Les textes ont mis en évidence une convergence significative sur les thèmes suivants : l'orientation sociale et critique, dans l'intérêt des sujets travailleurs; la complexité et les singularités qui régissent leurs expériences de travail; les processus de constitution, les engagements psychiques et politico-sociaux de ces travailleurs. Nous pensons qu'une synthèse des recherches présentées dans ce colloque reflète l'état actuel de la Psychologie du travail au Brésil, dans ses liens avec les Cliniques du travail et avec le champ de la Santé du travailleur.

This paper presents a brief discussion about Work psychology, in Brazil, and its interfaces with the Work clinics and the Worker's health field. Our starting point is the set of papers presented by Brazilian researchers in the "France-Latin America Symposium". A methodological cut has allowed us to elect these disciplinary fields by reading titles, reviews and paper references. The texts showed a significant convergence between the following themes: social and critical orientation, keeping interest in the working subjects ; the complexity and singularities that lead their work experiences; the processes of constitution, the psychic and political-social commitments of these workers. We believe that a synthesis of the researches presented in this colloquium reflects the current moment of the Work Psychology in Brazil, in its connections with the Work Clinics and the Worker's Health. 
ÍNDICE

Mots-clés: psychologie du travail, cliniques du travail, santé du travailleur, recherches brésiliennes

Palavras-chave: psicologia do trabalho, clínicas do trabalho, saúde do trabalhador, pesquisas brasileiras

Keywords: work psychology, work clinics, worker's health, brazilian researches

Palabras claves: psicología del trabajo, clínicas del trabajo, salud del trabajador, investigaciones brasileñas

\section{AUTORES}

\section{JOSÉ NEWTON GARCIA DE ARAÚJO}

Pontifícia Universidade Católica de Minas Gerais. Rua Grão Pará, 1060/101. Funcionários.

30.150-348. Belo Horizonte, Minas Gerais, Brasil. jinga@uol.com.br

\section{VANESSA ANDRADE DE BARROS}

Universidade Federal da Paraiba. Av. Maria Elizabeth, 265/302. Cabo Branco, 58.045-180, João

Pessoa, Paraiba- Brasil.vanessa.abarros@gmail.com. 